\title{
Specifics of human resources in non-profit organizations in the process of globalization
}

\author{
Eva Kicován ${ }^{1, *}$ \\ ${ }^{1}$ University of Zilina, Faculty of Operation and Economics of Transport and Communications, \\ Department of Economics, Univerzitna 1, 01026 Zilina, Slovak Republic
}

\begin{abstract}
Non-profit organizations carry out activities that the state either does not want to perform or does not take responsibilities for them due to financial reasons, and the private sector is not interested in them. Specific features of such kind organizations is the fact that their performance is mostly depended on the work of a man - a volunteer, so a human capital is their integral part. Volunteering is a multidimensional phenomenon. It is an important part of the society and its future development. The context of volunteering has changed in last years, because social trends as globalization, technological development, changes in demography, emergence of postmodern values, and changes in families and work change people's attitudes toward volunteering. In order a volunteer could realize his own personality and belief in volunteering activities and simultaneously participate in meeting goals of an organization, it is essential that all elements of management (organizing, managing, control, evaluating) are carried out effectively and have a meaning. To achieve this point, it is needed to know reasons, why people do volunteering that does not have only motivational sense, but also strategic one. Identifying motifs is therefore broader than just meeting needs and their knowledge is an essential factor for the effective functioning of non-profit organizations regardless of fields of their operation.
\end{abstract}

\section{Introduction}

The global aspect of the economy as well the progress and development of the technology are characterized by turbulent changes that except other are mirrored in the human resource management. Experts in human resource management deal with different tasks, except others they reflect on issues related to readiness to handle with generation transfers [1-5]. Generation transfers, in addition to the emerging young generation, also involve searching for talents, work-life balance, gender quality, continuous education and the creation and maintenance of competitive advantages. In the middle of interest of both profit and nonprofit organizations are human resources as the most valuable and precious kind of capital. The most of experts in human resources management prefer the opinion that personal matters are an integral part of management processes, cultural and social changes as well as the formation of organization cultures. The growing presence and positioning of the third sector organizations including their importance in the European and world context,

\footnotetext{
*Corresponding author : eva.kiccova@fpedas.uniza.sk
} 
provides a scope for exploring the personnel structure of this important pillar of the society, which has own specifics, but also certain parallels with the profit sector.

\section{Human resources management in non-profit organizations in process of globalization}

There is no longer any need to argue about the importance of the management and the need to manage human resources in non-profit organizations in the current period of global changes. The management must be linked with the vision, mission and strategic direction. A non-profit organization, like other organizations or systems, prepares own plans, strategies, takes decisions, hires employees, evaluates, motivates, and controls them.

Non-profit organization is one which is not driven by profit but by dedication to a given cause that is the target of all income beyond what it takes to run the organization. Nonprofit organizations are often used for trusts, cooperatives, advocacy, charity, environmental and religious groups. Many but not all not-profit organizations have paid staff in management positions; almost all use volunteers. They have no owners for surplus profits to go to and any surplus after operating expenses are used to further its goals instead of being distributed between members or employees of the organization. For a non-profit organization to qualify as a government-recognized and tax-exempt organization it has to fulfil conditions set out by government agencies [9].

Non-profits are not driven by generating profit, but they must bring in enough income to pursue their social goals. Non-profits are able to raise money in different ways. This includes income from donations from individual donors or foundations; sponsorship from corporations; government funding; programs, services or merchandise sales; and investments.[3]

Management is designed to achieve targets of an organization. Since the main part of an organization are people, by coordinating of their activities is possible to achieve such kind of results that individuals are not able to achieve. By definition, management should be present wherever there are people and targets.

The specific features characterize management of non-profit organizations. Based on the structured interview with managers of two non-profit organizations that operate in Žilina Region within the Slovak Republic, the features may be defined as:

- personal management is much more complicated due to existing personal structure in a non-profit organization, since the structure is composed not only by employees (who are paid for their work) but also by volunteers, and civilian workers,

- financial possibilities must be combined optimally so that there is no extreme dependence on one source of financing; the issue is also related to accounting and controlling,

- marketing - pricing, relationship building, and distribution have own specifics,

- problem solving, management of changes and decision-making process must accept specifics in the structure of human resources.

It can be stated that non-profit organizations are currently addressing the necessity of financing their activities and human resources issues. Nowadays, people are one of the most important sources of success for a company and play a significant role in achieving its targets. The correct setting of the strategy of managing human resources, motivating and communication are the basis for effective utilization of human potential [7].

For this reason, the survey further investigated, in particular, the specificities of personal management in non-profit organizations. These specificities can explained as following (based on the structured interview): 
- differentiated staff structure consisting of paid employees, volunteers and civilian workers; according to managers of non-profit organizations, volunteers are particularly,

- absence of rewards and sanctions in the work and motivation of volunteers, accumulating multiple, and usually too diverse, jobs into one,

- necessity of a "charismatic leader"; its importance is irreplaceable for the functioning of the organization.

We may consider volunteering as the most important source and driving force of nonprofit organizations. It is argued generally that while the market sector is depended on commercial pressure and the state needs rules, non-profit organizations are associated with the call for volunteering [6]. This is typical mainly for non-profit organizations that offer services, where the role of volunteer is consider to be the most important part of future success [2].

Although the term "capital" is rather reserved for economic discipline, we may work with it also at the level of immaterial or mental. Thus, unlike the economic form of capital, human capital acts as a creative actor of each organizations. Human capital with its own creative and uniqueness creates new products, services, controls their quality, distributes, and so fulfils targets and mission of an organization. Thus, with proper motivation, leadership and communication, human capital is a source of success and efficiency for each organization [4] Thereby it is needed to consider a man as a value that is an integral part of any organization. The value of a man is reflected in the following aspects:

- ability of a man to look for new ways of improvement, and self-realization,

- ability of a man to align with higher ideals and thereby participate in society,

- ability of a man to set people or things in motion; to transform own value into social power [11].

\section{Volunteering and its importance in managing human resources in non-profit organization}

As it has been noted above, an integral part of the third sector are volunteers. The word "volunteer" suggests that it is a sign for a person, who is trying to choose good or has a good will. He is therefore determined to do well.

About volunteering, it may be talked about it only when proceedings go beyond activities, which are routine. Crossing boundaries of a routine requires good will. A routine is an activity that is prescribed by our duty or the law. Where actions of a man exceed his own obligations, there begins volunteering. This shows that a man wants to achieve more good than can only be achieved by complying with the law and fulfilling his own obligations [1].

In the eyes of public, we can meet with different attitudes and opinions on the issue discussed. "Why do you participate in it for free?" "If you have a free time, I give you a paid part-time job, would you like?" "What does it bring you?" "Where a mistake has happened?" Why a young volunteer who is actively involved in the organization says: "I'm not voluntary, I just do it."

There are many definitions of volunteering. They vary according how it is approaching to them, what aspect of volunteering is being highlight, but also they depend on the culture and social environment of each country. One of these definitions considers volunteering as an outward-going activity where motivation is not money gains but the benefit of others [7]. The term volunteering may be defined as an activity that people carry out of own free will and for the benefit of others without claiming remuneration perceived in relation to the society on two levels. On the one hand, the society provides a space, in which a man may 
activate and satisfy own higher needs. On the other hand, the society would not be able to function without having the vision and desire to do something for benefit of others [8].

E.g. Svorcova emphasizes that volunteering is not a victim, but a natural expression of civil maturity. It brings a concrete help to those who need it, but at the same time gives a volunteer a sense of meaning, is a source of new experience and enrichment in interpersonal relationships [10].

Volunteering is a transfer of time and energy to the benefit of society, local community, individuals outside the immediate family, environment or other things. Voluntary activities are carried out of free will, for free, with the exception of reimbursement of own expenses. [1]. Volunteering is a driving force for changes for those who participate in volunteering as well as for a wide society. Based on the structured interview, volunteering is a non-paid and conscious activity that is done of own free will for the benefit of others. A volunteer may become every man in different areas of the life of society, where such kind of activities are needed $[12,13]$. Interesting is also the view that follows the above-mentioned view, but emphasizes that a volunteer is also an expert in his / her field selflessly providing his / her knowledge, skills and leisure to the benefit of others. The interviewed managers stated that volunteering in general is:

- based on personal motivation and free decision,

- specific form of support for active civic participation and interest in the community development,

- takes the form of a team activity, mostly within certain organization,

- increases a human potential and quality of daily life, support human solidarity,

- $\quad$ provides answers to important social challenges and contributes to creating better and more peaceful word.

\section{Challenges in human resources management in non-profit organizations in process of globalisation in conditions of Slovak Republic}

Globalization is characterized (inter alia) by strengthening democratization processes, increasing the impact of social networks, and emerging of non-profit organizations of various kinds, in particular with the support of the Nordic governments, as well as strengthening the cooperation between the profitable, governmental, and social sector in Western Europe.

Non-profit organizations except standard and specific actions in the area of human resources management have to deal with differences between the XYZ generations and adapt their recruiting processes, review working conditions, forms of employee evaluation and consider offering possibilities to gain new working experience. Managing the management of mixed groups and teams of diverse staff is important.

The globalization brings not only the different generations, but also many other challenges. Based on some material, the European organizations in managing human resources will face following challenges in the close future: lack of talent, aging population, work-life balance, change management and cultural transformation [14-16].

A particularly sensitive issue related to the labour, including child labour, is the exploitation in the form of inadequate wages, undignified, dangerous or even health and life-threatening conditions. In this context, organizations of the non-profit sector, the media, basically, each individual play an irreplaceable role.

The non-profit sector in Slovakia in most cases progresses successfully mainly thanks to corporate philanthropy and donation, volunteering as well as individual contributors [17]. On the other hand, it must be stated that it still lacks an adequate awareness and a clear legal framework. 
Corporate social responsibility is gradually becoming an integral part of the corporate culture, which is increasingly communicated both internally and externally [18]. This is reflected in the increased involvement of employees in volunteering activities. Responsible entrepreneurship is no longer just a trendy business, but more and more companies in the profit sector see it as own benefits to their own business, to the selected community or group they support [19]. Corporate social responsibility is now becoming a matter of prestige.

\section{Conclusion}

In the middle of interest of managers of human resources and strategies of the non-profit sector are problems dealing with sources and their effectiveness. Their solutions require transparent and sensitive approach that is supported by responsible entrepreneurship both towards nature and towards people. The increasing social, property and educational differences, together with a change in the hierarchy of social values and priorities, as well as an aging population on the European continent, call for relevant responses to the situation. While there are multiple obstacles in the labour market, new opportunities are also uncovered. Thanks to new opportunities, it is possible to implement new form of education processes in the schools and organizations, which will copy the actual needs in the labour market and react flexibly to them. In addition to new information and technologies, managers of human resources as well as employees themselves, will have to cope with new situation in groups and teams, where people of different generations and culture will meet.

Grant No. 1/0544/19 Formation of the methodological platform to measure and assess the effectiveness and financial status of non-profit organizations in the Slovak Republic.

\section{References}

1. M. G. Abadia, J. Lin, Nonprofit cost analysis Toolkit: Six steps to finding the true costs of programs. The Bridgespan Group. Available at: https://www.bridgespan.org/bridgespan/Images/articles/nonprofitcost-analysistoolkit/NonprofitCostsAnalysisToolkit.pdf (2018)

2. S. Cabral, J. T. Mahoney, A. M. McGahab, Value creation and value appropriation in public and nonprofit organizations, Stragegic management Jurnal 40, 465-475 (2019)

3. L'. Gajanová, The proposal of competitive intelligence model for enterprises in the Slovak republic as a prerequisite for sustainable development in a global environment, Globalization and its socio-economic consequences: 15th international scientific conference : proceedings: 7th-8th October 2015 Rajecke Teplice, Slovak republic. Part I. - Zilina: ZU - University of Zilina, 135-143, (2015)

4. J. Klieštiková, D. Moravčíková, The power of giving back [print]: case study of Slovak Republic, 4th International conference on Economic, Business Management and Education Inovation (EBMEI 2017), 1, (2017)

5. M. J. Lai , L. Y. Tang, How non-profit organization contribute to change: developing new 2.0 Taiwan dementia plan in response to the WHO global action plan, International psychogeriatrics, 31, 149-149, (2019)

6. A. I. Leber, J. Borocki, J. Radisic, B. Slusarczyk, Fostering Alliances with Customers for the Sustainable Product Creation, Sustainability. 10(9), 3204 (2017) 
7. J. Mazanec, V. Bartošová, Financial vulnerability of non-profit organizations in the Slovak Republic, Education excellence and innovation management through Vision 2020 proceedings of the 33rd International business information management association conference, International business information management association, $\mathbf{1}$, 1051-1066 (2019)

8. C. Miller, Hidden in Plain Sight: Understanding Nonprofit Capital Structure. The nonprofit Quarterly, Online: http://www.nonprofitfinancefund.org/report/hidden-plainsight-understandingnonprofit-capital-structure (2003)

9. L. Michalková, T. Klieštik, Optimizing the selection of investment projects based on adjusted net present value, 5th International conference on applied social science Bellflower: Information engineering research institute, 1, 298-304 (2017)

10. C. M. Mularz, M. A: Ülkü, Analytics for Nonprofits, Encyclopaedia of Business Analytics and Optimization, 115-123 (2014).

11. M. Nadányiová, P. Durana, Corporate social responsibility as a brand value-enhancing tool, 8th International scientific symposium economy of eastern Croatia - vision and growth, 1, 1225-1237, (2019)

12. B. Never, Divergent Patterns of Nonprofit Financial Distress. Nonprofit Policy Forum, 5 (1), 67-84. (2013)

13. M. Turcotte, Spotlight on Canadians: Results from the General Social Survey. Volunteering and charitable giving in Canada, 18. Available at: http://www.statcan.gc.ca/pub/89-652-x/89-652-x2015001-eng.pdf, (2015).

14. V. Valjašková, J. Klieštiková, The main aspects of brand portfolio management, 8th International scientific symposium economy of eastern Croatia - vision and growth, $\mathbf{1}$, 1253-1260 (2019).

15. M. Nadanyiova, Japanese management and its practice in company branch based in Slovakia. In 8th International Scientific Conference on Business and Management (Vilnius, Lithuania, 546-554, 2014)

16. M. Poliak, A. Krizanova, S. Semanova, L. Stefanikova, The impact of procurement method of the transport services to the financial requirement of performance contracting entity. Transport problems 8, 4, 67-76 (2013) 3x

17. H. Spech, Why should a non-profit organization be attractive for an investor?, TRUSTS \& TRUSTEES, 25, 6, 643-649 (2019)

18. J. Majerova, Analysis of Specifics in Buying Behavior of Slovak Customers in Internet Environment. In 2nd International Conference on Social Sciences Research (Hong Kong, China, 172-178, 2014)

19. W. Sroka, J. Cygler, B. Gajdzik, The Transfer of Knowledge in Intra-Organizational Networks: A Case Study Analysis. Organizacija 47, 1, 24-34 (2014) 